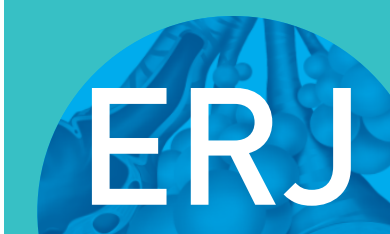

open research
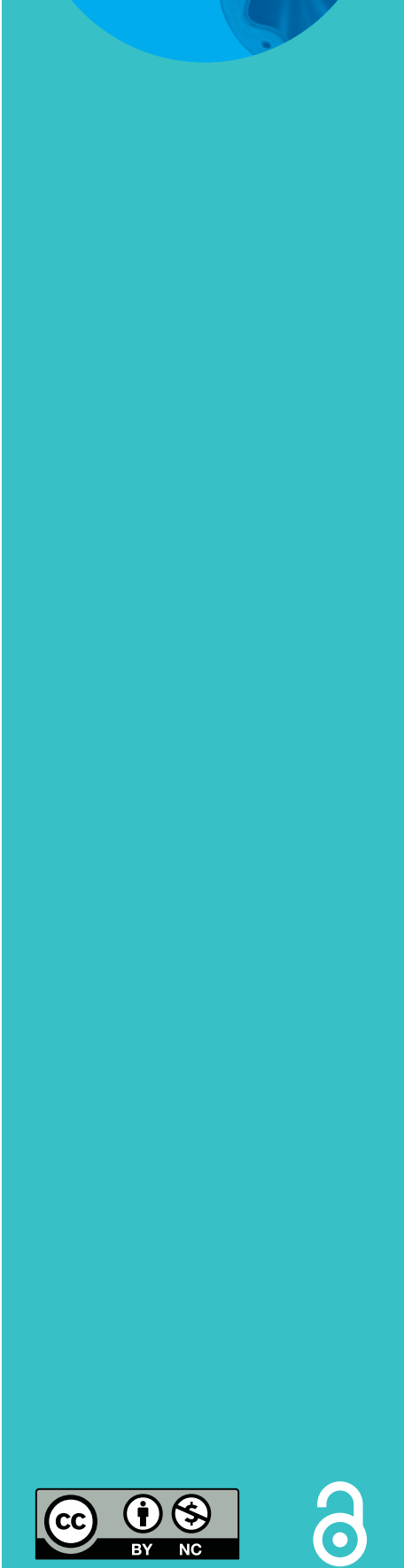

\section{Pathophysiology and potential future therapeutic targets using preclinical models of COVID-19}

\author{
Rahul Kumar $\mathbb{1}^{1}$, Michael H. Lee ${ }^{1}$, Claudia Mickael², Biruk Kassa, \\ Qadar Pasha ${ }^{3}$, Rubin Tuder ${ }^{2}$ and Brian Graham (1) ${ }^{1}$
}

Affiliations: ${ }^{1}$ Dept of Medicine, Division of Pulmonary and Critical Care Medicine, University of California San Francisco, San Francisco, CA, USA. ${ }^{2}$ Dept of Medicine, Division of Pulmonary Sciences and Critical Care Medicine, University of Colorado Anschutz Medical Campus, Aurora, CO, USA. ${ }^{3}$ Functional Genomics Unit, CSIR-Institute of Genomics and Integrative Biology, Delhi, India.

Correspondence: Rahul Kumar, Pulmonary and Critical Care Medicine, University of California San Francisco, San Francisco, CA 94110, USA. E-mail: rahul.kumar2aucsf.edu

ABSTRACT Severe acute respiratory syndrome-coronavirus-2 (SARS-CoV-2) gains entry into the lung epithelial cells by binding to the surface protein angiotensin-converting enzyme 2. Severe SARS-CoV-2 infection, also known as coronavirus disease 2019 (COVID-19), can lead to death due to acute respiratory distress syndrome mediated by inflammatory immune cells and cytokines. In this review, we discuss the molecular and biochemical bases of the interaction between SARS-CoV-2 and human cells, and in doing so we highlight knowledge gaps currently precluding development of new effective therapies. In particular, discovery of novel treatment targets in COVID-19 will start from understanding pathologic changes based on a large number of autopsy lung tissue samples. Pathogenetic roles of potential molecular targets identified in human lung tissues must be validated in established animal models. Overall, this stepwise approach will enable appropriate selection of candidate therapeutic modalities targeting SARS-CoV2 and the host inflammatory response.

@ERSpublications

A large number of autopsy samples and reliable preclinical animal models are required to understand the inflammatory process in \#COVID19 https://bit.ly/3jWUVp4

Cite this article as: Kumar $\mathrm{R}$, Lee $\mathrm{MH}$, Mickael $\mathrm{C}$, et al. Pathophysiology and potential future therapeutic targets using preclinical models of COVID-19. ERJ Open Res 2020; 6: 00405-2020 [https://doi.org/10.1183/23120541.00405-2020].

Received: 20 June 2020 | Accepted after revision: 27 Oct 2020

Copyright $\odot$ ERS 2020. This article is open access and distributed under the terms of the Creative Commons Attribution Non-Commercial Licence 4.0. 


\section{Introduction}

The novel coronavirus disease 2019 (COVID-19) caused by severe acute respiratory syndrome-coronavirus-2 (SARS-CoV-2) was first identified in Wuhan, China and quickly spread to become a pandemic. As of 1 September, 2020, the World Health Organization reported over 25 million confirmed cases of COVID-19 worldwide, resulting in more than 850000 deaths globally and 180000 deaths in the USA alone [1].

The clinical symptoms and pathobiology of COVID-19 are similar to those seen in infections caused by another coronavirus, severe acute respiratory syndrome-coronavirus (SARS-CoV), which globally resulted in approximately 774 deaths in 2003 [2]. Recent studies have identified that similar to SARS-CoV, SARS-CoV-2 binds to a specific human cell surface protein, angiotensin-converting enzyme 2 (ACE2). ACE2 is expressed by multiple cell types including the epithelial cells of the lungs, the intestine, the

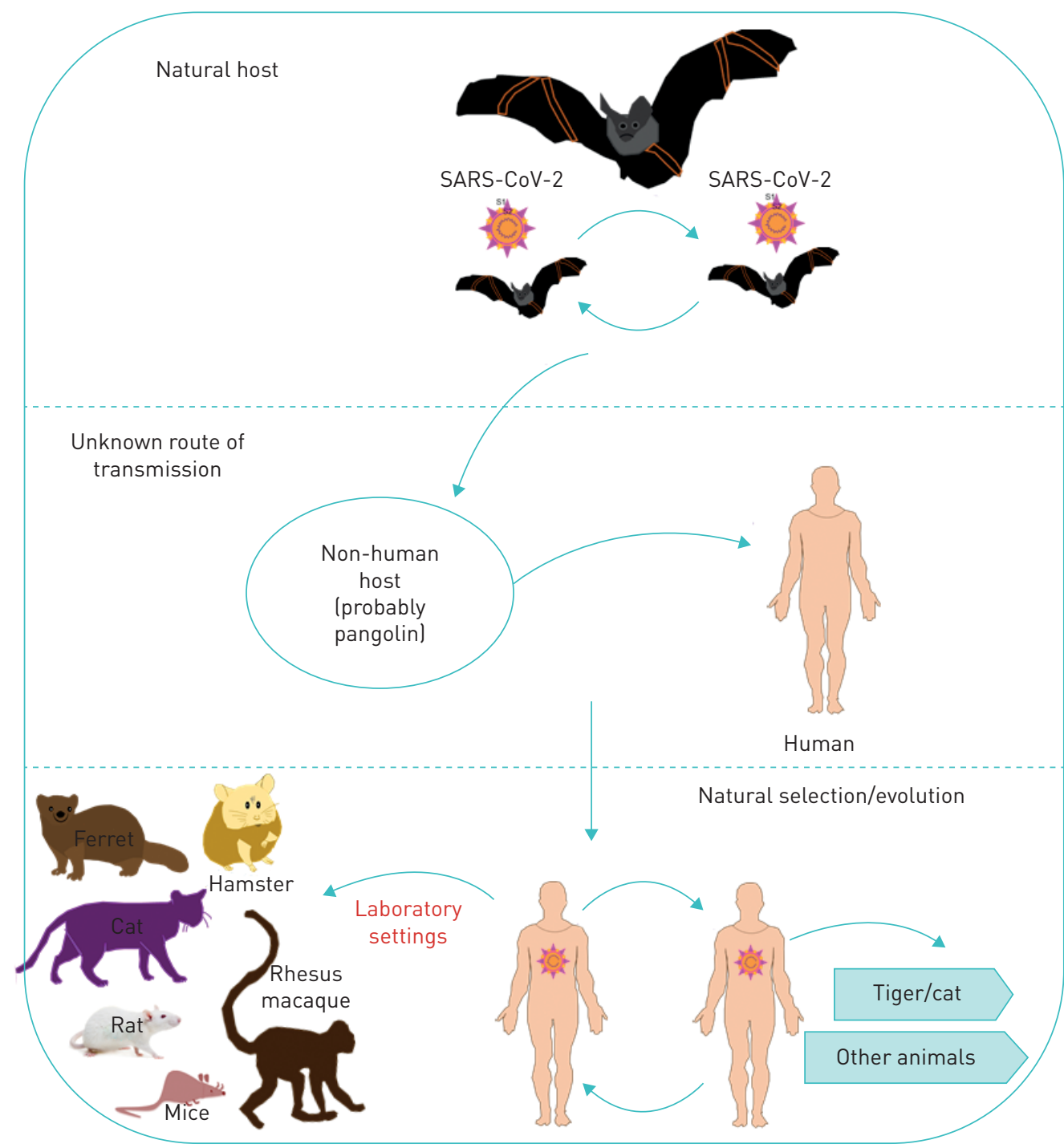

FIGURE 1 Life cycle of severe acute respiratory syndrome-coronavirus-2 (SARS-CoV-2). Based on the phylogenetic study, transmission of SARS-CoV-2 evolves from the natural reservoir of bats (non-human host) to the current pathogenic state of human outbreak through natural selection or another mammal, probably pangolin $[15,16]$ served as a host of a non-pathogenic version of the SARS-CoV-2 that later jumped into humans with the acquired capacity to current pandemic outbreak through human-to-human transmission [12, 19]. The viral ability to infect small and large animals under laboratory settings points to animals as an intermediate natural host $[17,18]$. Based on a Centers for Disease Control and Prevention report, a very small number of pets, including dogs and cats, outside the USA were reported to be infected with the virus that causes coronavirus disease 2019 (COVID-19) after close contact with people with COVID-19. However, a tiger at a zoo and two pet cats in New York (NY, USA) have also tested positive for SARS-CoV-2 [18]. 
kidneys and endothelial cells [3]. Although multiple clinical trials are underway targeting various aspects of the viral replication cycle and host immune response, COVID-19 continues to spread, resulting in devastating medical and socioeconomic consequences worldwide.

Considering that SARS-CoV-2 in severe cases activates a multitude of inflammatory immune cells leading to a cytokine storm, it is not surprising that the strategy of targeting one particular inflammatory signal has not been shown to be highly efficacious in trials [4]. Moreover, long-term consequences in recovered patients or asymptomatic carriers remain uncertain. These shortcomings can be addressed by utilising animal models that recapitulate COVID-19-related pathological characteristics in humans. Recently, multiple animal models such as mice [5-7], Syrian golden hamsters [8], ferrets [9] and nonhuman primates [10], have been utilised to evaluate the COVID-19 related pathology. Despite their inherent limitations, these animal models represent powerful tools that will allow us to conduct mechanistic studies of disease pathogenesis, identify key therapeutic targets, and test efficacies of potential therapeutic interventions. In this review we highlight the overall pulmonary pathophysiology of COVID-19, and provide an overview of animal models well-suited for mechanistic studies and preclinical therapeutic trials.

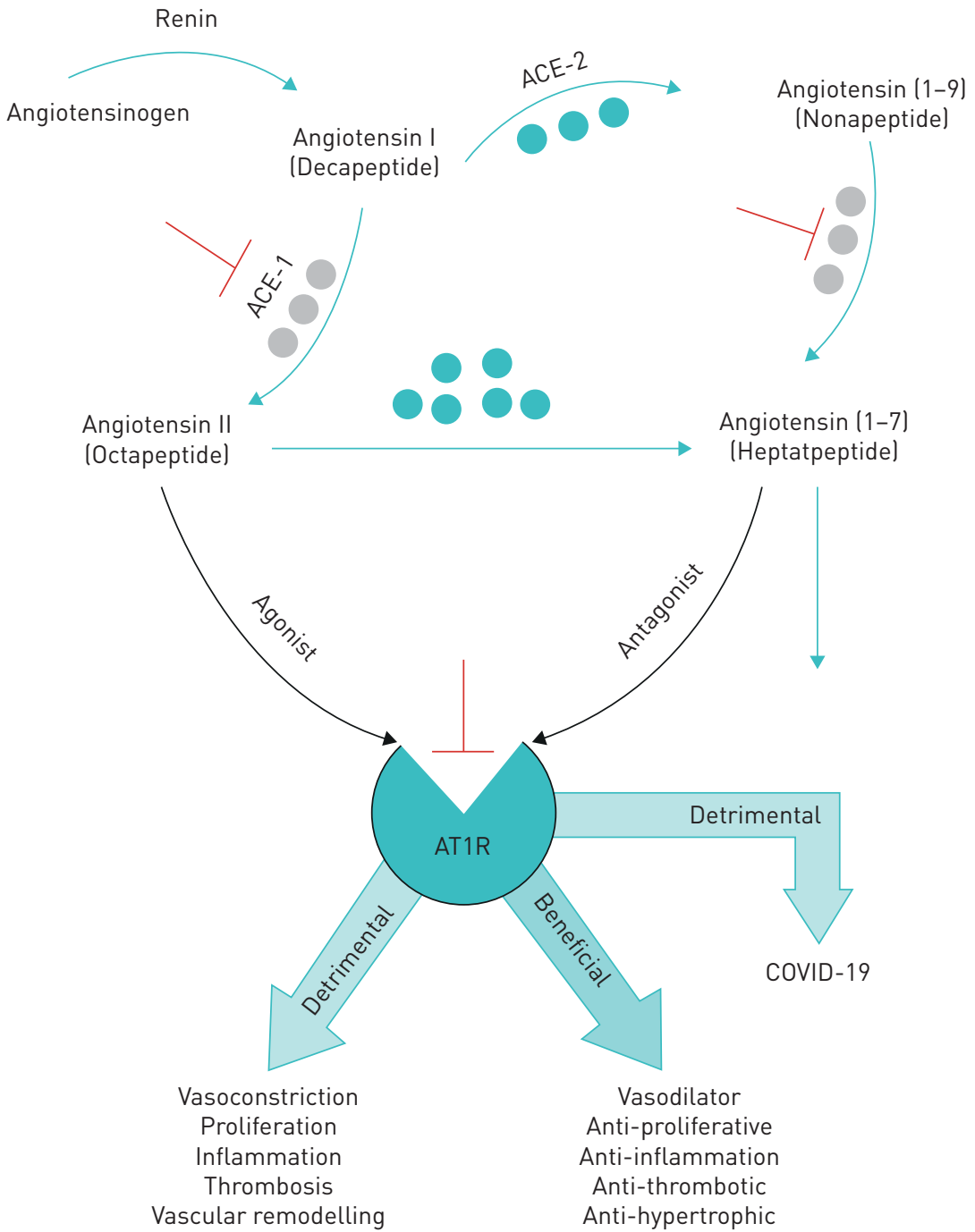

FIGURE 2 Angiotensin-converting enzyme 2 (ACE2)-mediated counter regulation of the renin-angiotensin system (RAS). The ACE2-angiotensin (1-7) Mas axis (right side) counterbalances the harmful effects of the ACE1-angiotensin II type 1 receptors (AT1R) axis (left side). Angiotensinogen gets converted into angiotensin-I through enzymatic action of renin. ACE2 degrades angiotensin II and generates angiotensin (1-7) which antagonises the effects of angiotensin II. Moreover, clinical evidence suggests that RAS blockade by ACE inhibitors or AT1R blockers and mineralocorticoid antagonists enhance ACE2 level that is ultimately beneficial to the patients with cardiovascular diseases [23-26] but deleterious for coronavirus disease 2019 (COVID-19] patients $[17,22,27]$. The ACE inhibitor and angiotensin receptor blockers (as shown in red) antagonise the angiotensin II/AT1R axis. 


\section{Origin of SARS-COV-2 and mode of transmission to humans}

SARS-CoV-2 is the seventh member of Coronaviruses, a large family of single-stranded enveloped RNA viruses with sizes ranging from 80 to 120 nanometers in diameter [11]. Comparative phylogenetic analyses revealed a close resemblance between SARS-CoV-2 and SARS-like bat viruses, suggesting that these bat viruses most likely serve as reservoir hosts for SARS-CoV-2 progenitor. Initially, critical mutations likely provided the capability to infect an intermediate non-human mammal [12-15]. The virus presumably continued to evolve through natural selection to acquire both the ability to infect humans and the capacity for efficient human-to-human transmission (figure 1) [13]. Based on the ability of SARS-CoV-2 to infect animals in both natural and experimental environments and the lack of evidence demonstrating direct bat to human transmission, it has been suggested that pangolins served as intermediate hosts between bats and humans [16].

\section{ACE2: a portal of entry for SARS-CoV-2}

Infection of mammalian cells occurs through the virus binding to cell surface proteins, with a critical interaction between the spike glycoprotein on SARS-CoV-2 and the mammalian ACE2 surface protein [17]. Once the virus binds to host ACE2, a furin cleavage site on the viral spike protein facilitates viral entry into the host cells [13].

ACE2 is ubiquitously expressed on the surface of alveolar epithelial type I and type II cells [3]. ACE2, like ACE, is a key protein of the renin-angiotensin system (RAS), which contributes to vascular homeostasis; ACE2 dysregulation under pathological conditions leads to multiple cardiovascular abnormalities [20, 21]. Classic physiological functions of ACE and ACE2 in the RAS are summarised in figure 2. Briefly, cleavage of angiotensin-I by ACE generates angiotensin-II, a peptide that triggers a multitude of pathologic signalling through the angiotensin-II type 1 receptor (AT1R), resulting in vasoconstriction, cell proliferation, inflammation, thrombosis, and vascular remodelling [28, 29]. These pathogenetic effects of ACE/angiotensin-II/AT1R axis are counterbalanced by a cardioprotective signalling axis, in which cleavage of angiotensin-II by ACE2 generates angiotensin 1-7, peptides with Mas receptor-mediated anti-inflammatory, anti-apoptotic, anti-thrombotic and vasodilatory properties.

This normally protective enzyme ACE2 is exploited by SARS-CoV-2, serving as a portal of viral entry into mammalian cells. A schematic of the series of events underlying the viral infection of host cells is shown in figure 3. Both SARS-CoV and SARS-CoV-2 belong to the $\beta$-genus of Coronaviruses and share $\sim 80 \%$ homology [35]. Despite substantial genetic and structural similarities between the two coronaviruses, the spike protein of SARS-CoV-2 has a stronger binding affinity for ACE2, which may underlie the greater transmissibility of SARS-CoV-2 and the more pronounced clinical impact of COVID-19 [36, 37].

The spike glycoprotein protruding out from the SARS-CoV-2 transmembrane surface forms homotrimers. Each spike glycoprotein is comprised of two functional subunits, S1 and S2. The distal S1 subunit contains a receptor binding domain (RBD) that exclusively facilitates binding of the viral envelope to the transmembrane ACE2 protein on the host cells [38]. The membrane-anchored S2 subunit allows fusion of the viral and host cellular membranes, resulting in delivery of the viral nucleocapsid into the cytoplasm of the target cell.

The binding affinity of SARS-CoV-2 for ACE2 and its entry into host cells are modulated by multiple proteases expressed by host cells, including cathepsins L and B, trypsin, factor X, elastase, furin and transmembrane protease serine 2 (TMPRSS2) [11, 39-42]. TMPRSS2 cleaves the viral S2 subunit at a site immediately upstream of the peptide sequence that facilitates virus-host cell fusion [11]. This cleavage results in an irreversible conformational change of the S2 glycoprotein, ultimately resulting in more efficient viral entry into the host cell $[11,22]$. A recent study showed that blockade of TMPRSS2 activity attenuates SARS-CoV-2 entry into host cells, suggesting inhibitors of TMPRSS2 may serve as therapeutic approaches [43]

Recent studies have reported a higher prevalence of hypertension and diabetes in COVID-19 patients [44-46], which could partially reflect their altered ACE2 expression. While ACE2 protects against the potentially detrimental effects of unopposed RAS by limiting substrate availability for the ACE/ angiotensin-II/AT1 receptor axis, there is compensatory increased expression of ACE2 following the use of pharmacologic ACE inhibitors (ACEIs) and angiotensin receptor blockers (ARBs). These medications cause an approximately three- to five-fold increase in ACE2 expression [47]. This increased expression of the host viral entry protein could hypothetically augment ACE2-mediated viral infection. However, the true clinical impact of these medications in the context of COVID-19 remains uncertain, and whether ACE inhibitors or ARBs should be stopped in those infected with SARS-CoV-2, or potentially even started as an anti-viral adjunctive therapy, is currently hotly debated [48-50]. The potential benefit of these medications is that ACEI-mediated inhibition of ACE could, through a negative feedback loop, limit local 
tissue accumulation of angiotensin-II, thereby decreasing the overall severity of inflammation [51, 52]. For example, multiple studies have shown that RAS inhibitors effectively suppress the symptoms of acute severe pneumonia in other settings, and thus could be beneficial in patients with COVID-19 [52-55]. These conflicting theoretical risks and benefits, and the lack of robust clinical data on their overall effect in COVID-19 patients with underlying cardiovascular comorbidities preclude drawing a firm conclusion regarding the clinical use of ACEIs and ARBs in the context of COVID-19.

As discussed below, the pathogenesis of COVID-19 involves a number of pathophysiologic processes including dysregulated innate and adaptive immune responses and upregulated expression of inflammatory cytokines, culminating as acute respiratory distress syndrome (ARDS). It is worthwhile to note that ACE2 has been shown to be implicated in regulating all these processes [53, 56, 57]. Studies have shown higher risk of mortality in COVID-19 patients with cardiovascular comorbidities, but with no correlation between the use of ACEIs/ARBs and patient morbidity and mortality [58]. Therefore, in the absence of data to the contrary, it seems logical to continue RAS inhibitors in hypertensive patients, as was also suggested by another recent review [59]. In summary, the current consensus is that previously prescribed RAS inhibitors should be continued in hypertensive patients with known or suspected COVID-19.

\section{Role of animal models in elucidating the pathogenesis of COVID-19}

Pre-clinical models are critical to facilitate the selection of candidate therapeutic approaches for clinical trials. One approach relies on in vitro model systems, such as pseudoviral infection assays and direct examination of cells and tissues harvested from COVID-19 patients, which can take place in biosafety level-2 settings, or biosafety level-3 when dealing directly with viral samples. In this section, we focus on another important investigational tool in COVID-19 research: utilisation of in vivo animal models that can recapitulate key clinical or pathological characteristics of COVID-19. A major challenge in COVID-19 research is the currently limited understanding of the series of events that link the initial upper respiratory tract infection to the subsequent development of lower respiratory tract infection and ARDS. Thus, establishment of robust and reproducible COVID-19 animal models may elucidate pathogenetic mechanisms leading to the development of effective therapeutic targets.

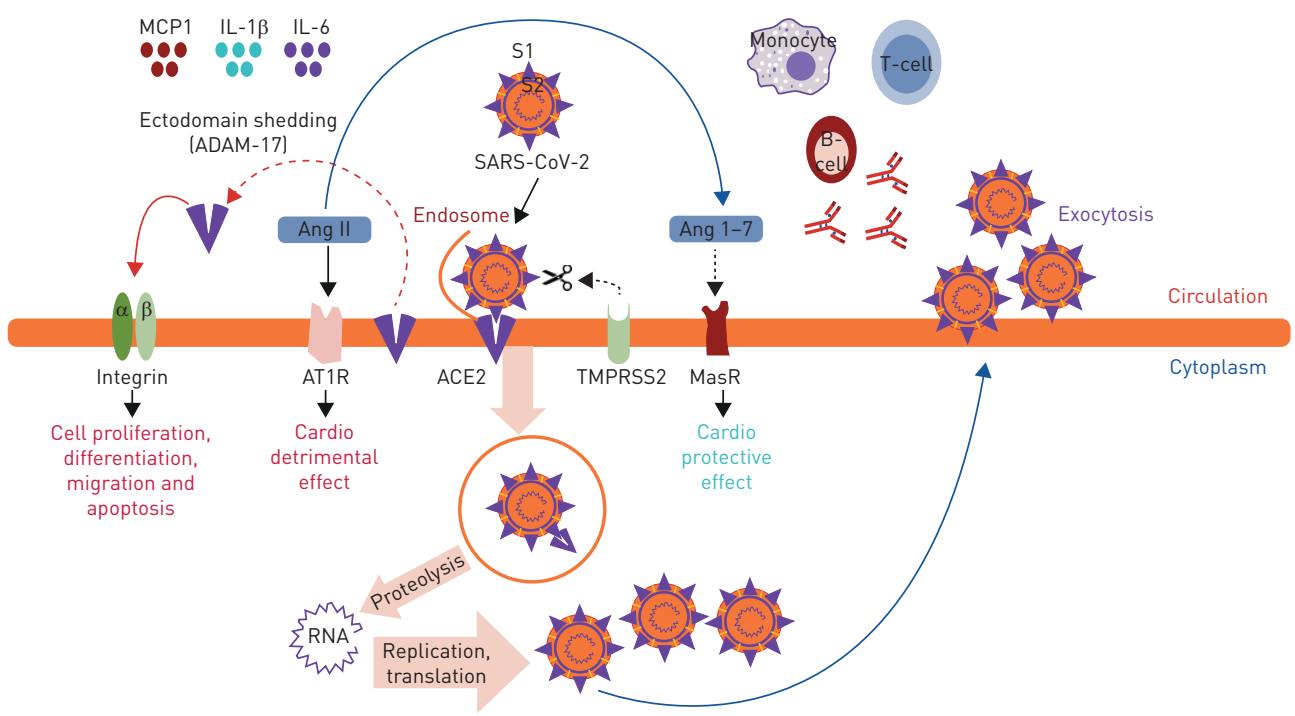

FIGURE 3 Biological mechanism of severe acute respiratory syndrome-coronavirus-2 (SARS-CoV-2) infection. Once the SARS-CoV-2 approaches the cell membrane, basal S1 subunit of viral spike glycoprotein binds to a membrane-bound molecule of angiotensin-converting enzyme 2 (ACE2). As more S1 subunits binds to membrane-bound molecules of ACE2, the membrane starts to form an envelope around the virus lan endosome). A cell membrane-bound serine protease, TMPRSS2, cleaves the S1 subunits of SARS-CoV-2 from its S2 subunits that mediated endosome entry into the cells (endocytosis). Inside the cell, viral genetic material is released by either acidification or by proteolysis (cathepsin). Viral replication and translation forms a new virion that cleaves out from cells by exocytosis. Of note, ACE2-mediated cardiovascular protection is lost following endocytosis of ACE2 with SARS-CoV-2 viral particles. The endocytosis triggers ADAM-17-mediated ectodomain shedding of tissue ACE2 [30,31], which through the integrin pathway induces pathologic intracellular signalling [32]. Lack of ACE2 availability increases angiotensin II levels that result in detrimental effects due to increased activity of angiotensin-II type 1 receptor (AT1R) at the expense of ACE2/ angiotensin (Ang) 1-7 driven protective pathways [34]. Viral infection also results in activation of circulatory inflammatory cytokines, antibody response and immune cells; these may damage airways epithelia. IL: interleukin; MCP: monocyte chemotactic protein 1. 
Historically, mouse models have been extensively used to explore molecular and pathological mechanisms involved in various infectious as well as non-infectious diseases. Specifically, mouse models were previously utilised to investigate diseases caused by other coronaviruses, for example severe acute respiratory syndrome (SARS caused by SARS-CoV-1) and Middle East respiratory syndrome (MERS) [60-62]. These former studies strongly support the promising role of mouse models in COVID-19 research. In addition to the relatively fast reproductive rates and low maintenance costs, another key advantage of using mouse models is the accessibility to numerous inbred and transgenic lines harbouring genetic changes that can be inducible and cell-type specific. Examples of currently available mice well-suited for SARS-CoV-2 investigation include knockout models of the following genes: Ace $2^{-1-}$, Tmprss $2^{-/-}, I L-6^{-/-}$, and $I N F-\gamma^{-/-}$. Inducible and cell compartment specific deletion can be used to determine the precise roles of lung epithelial and endothelial cells underlying the crosstalk between the capillary endothelial cells and the alveolar epithelium in SARS-CoV-2 infection in COVID-19. Simultaneously, transgenic mice lacking the TMPRSS2 protein might be helpful in understanding the effect of different therapeutic approaches against SARS-CoV-2 alone or in combination with TMPRSS2 blockade [63]. Aged or inbred mice with chronic underlying disease phenotypes, such as hypertension or diabetes, can be used to understand potential drivers of age and comorbid conditions on higher mortality rates in COVID-19. Of note, these mouse models have been used for many years to understand the molecular or immune pathobiology of other pulmonary pathologies, including ARDS, thrombosis, fibrosis and vasculopathy, all aspects of COVID-19 disease. Key features of mouse models used in studies of coronavirus infections, including SARS-CoV-2, are summarised in table 1.

While mouse models are valuable tools in uncovering pathobiological mechanisms of SARS-CoV-2 infection, mouse models are also characterised by important limitations. One key limitation of mouse models of COVID-19 is their relatively mild disease phenotype owing to the inability of SARS-CoV-2 to utilise the mouse orthologue of the human ACE2 (hACE2) [67]. In response, the hACE2 transgenic mouse model was previously developed to study SARS-CoV, which has now been recently repurposed for investigating the pathogenesis of SARS-CoV-2 infection [6, 7]. Critically, the hACE2 mouse model upon SARS-CoV-2 infection recapitulates the lung pathologies observed in COVID-19 patients, such as interstitial pneumonia with significant infiltration of macrophages and lymphocytes into the alveolar interstitium, with a phenotype of diffuse alveolar damage and ARDS [6]; major drivers of death in COVID-19 [53, 64, 66]. Recently another reliable mouse model incorporating adeno-associated virus-mediated hACE2 expression was developed [5]. Another major limitation of mouse models is the inherent different between the immune systems of mice and those of humans. This shortcoming can, in part, be overcome by utilising humanised mice (e.g. mice with human peripheral blood mononuclear cells, or huPBMC-NOG), which represents a useful approach to studying the contribution of various immune cells to COVID-19.

Hamsters and ferrets demonstrate disease phenotypes closer to those of humans without requiring transgenic modification. Hamsters infected with SARS-CoV-2 recapitulate key elements of the human lung pathology seen in severe cases of COVID-19, including inflammation, diffuse alveolar damage, peripheral lymphopenia, and marked activation of the innate immune response including high levels of chemokines and other cytokines [68]. Interestingly, conferring passive immunity by transferring sera from recovered hamsters to recipient hamsters newly infected with SARS-CoV-2 led to attenuated viral replications but without a significant reduction in lung pathology [68], data supportive of the clinical use of convalescent plasma.

Ferrets can also be infected with SARS-CoV-2, resulting in fever and relatively mild lung disease. Ferret-to-ferret SARS-CoV-2 transmission has been reported, suggesting ferrets may be well-suited for studying prophylactic treatments. One major limitation of hamster and ferret models is that all animals uniformly recover following SARS-CoV-2 infection, precluding their clinical relevance to more severe forms of COVID-19 clinical disease characterised by severe ARDS resulting in death. Therefore, both hamster and ferret SARS-CoV-2 models may be most applicable to humans with mild clinical disease or asymptomatic carriers.

Pathologic changes in nonhuman primates typically phenocopy those in human diseases, and for this reason nonhuman primates are considered the gold standard for testing vaccines and therapeutic strategies. In a prior study of Chinese rhesus monkeys (Macaca mulatta), SARS-CoV infection led to the development of neutralising antibodies again the SARS spike glycoprotein; paradoxically, the anti-spike neutralising antibody response occurred significantly faster in monkeys that ultimately died when compared to those that recovered $[69,70]$. These data suggest that anti-spike-immunoglobulin $G$ may contribute to a more severe ARDS phenotype, such as by downregulating an anti-inflammatory response [69]. 
Nonhuman primate models previously used to study SARS-CoV infection have now been repurposed to study SARS-CoV-2 [71-73]. One study showed more pronounced viral shedding in the upper respiratory tract of aged animals as compared to younger animals following intranasal SARS-CoV-2 inoculation [10]. Of note, a similar association between viral shedding and age has been observed in humans with both SARS-CoV and SARS-CoV-2 infections $[74,75]$. Although the higher maintenance cost, longer reproductive period, more rigorous ethical and regulatory oversight, and the lack of readily available transgenic variants limits the ability to widely use nonhuman primates to study SARS-CoV-2, their close resemblance to humans and specifically their similar immune system makes them a powerful model system, potentially in particular for vaccine development [76].

\section{The pulmonary pathophysiology of COVID-19}

SARS-CoV-2 infection involves both the upper and lower respiratory tracts. Approximately $80 \%$ of patients with COVID-19 do not require hospitalisation, as their symptoms are relatively mild, and their immune systems effectively contain the virus within the upper respiratory tract $[18,77]$. In the remaining $20 \%$ of patients, the viral infection progresses to involve the lower respiratory tract, resulting in pneumonia [77]. Approximately 6\% of COVID patients with pneumonia develop respiratory failure requiring admission to the intensive care unit (ICU) for support due to ARDS [78, 79]. The time from disease onset to death in fatal cases ranges from 15 to 52 days [80].

TABLE 1 Key features of mouse models used in studies of coronavirus infections

\begin{tabular}{|c|c|c|c|}
\hline Mouse line & $\begin{array}{l}\text { Disease } \\
\text { model }\end{array}$ & Key findings & [Ref.] \\
\hline \multirow[t]{2}{*}{ Wildtype } & SARS & $\begin{array}{l}\text { SARS-CoV infections resulted into shedding of large amounts } \\
\text { of infectious virus with the development of lung injury due to } \\
\text { lowering of ACE2 expression }\end{array}$ & [64] \\
\hline & SARS & $\begin{array}{l}\text { SARS-CoV-infected } \mathrm{C}^{-1-} \text { mice exhibited significantly less } \\
\text { weight loss and less respiratory dysfunction with reduced } \\
\text { lung pathology and lower cytokine and chemokine levels in } \\
\text { both the lungs and the sera }\end{array}$ & [65] \\
\hline \multirow[t]{2}{*}{$A c e 2^{-/-}$} & SARS & $\begin{array}{l}\text { SARS-CoV infections resulted in less shedding infectious virus } \\
\text { with mild lung pathological changes due to reduced amount } \\
\text { of spike RNA }\end{array}$ & [64] \\
\hline & ARDS/SARS & $\begin{array}{l}\text { ACE2 blockade in mice resulted into enhanced vascular } \\
\text { permeability, increased lung oedema, neutrophil } \\
\text { accumulation, and worsened lung function }\end{array}$ & $\begin{array}{l}{[53,} \\
64]\end{array}$ \\
\hline \multirow[t]{2}{*}{ Tmprss2 $^{-/-}$} & SARS & $\begin{array}{l}\text { SARS-CoV infection in Tmprss } 2^{-/-} \text {mice showed attenuated } \\
\text { inflammatory chemokine and/or cytokine responses }\end{array}$ & [33] \\
\hline & COVID-19 & $\begin{array}{l}\text { Transcriptional downregulation of Tmprss2 inhibits host } \\
\text { SARS-CoV-2 entry. }\end{array}$ & [63] \\
\hline $\begin{array}{l}\text { Tmprss2 }^{-/-} \\
\quad \text { hDPP4-Tg }\end{array}$ & MERS & $\begin{array}{l}\text { Tmprss } 2^{-/-} \text {murine models infected by MERS-CoV showed } \\
\text { improved immunopathology }\end{array}$ & [33] \\
\hline hACE2 & COVID-19 & $\begin{array}{l}\text { Mouse model of COVID-19 showing similar pattern of human } \\
\text { interstitial pneumonia with infiltration of significant } \\
\text { macrophages and lymphocytes into the alveolar interstitium, } \\
\text { and accumulation of macrophages in alveolar cavities } \\
\text { following SARS-CoV-2 infection }\end{array}$ & $\begin{array}{l}{[6,7,} \\
66]\end{array}$ \\
\hline \multirow[t]{2}{*}{ hACE2 } & COVID-19 & $\begin{array}{l}\text { This model developed productive SARS-CoV-2 infection and } \\
\text { inflammatory pulmonary infiltrates as seen in COVID-19 } \\
\text { patients }\end{array}$ & [5] \\
\hline & & $\begin{array}{l}\text { Evidence of inadequate antiviral activity and potential harms of } \\
\text { endogenous type I IFN responses were observed }\end{array}$ & \\
\hline $\mathrm{C} 3^{-1-}$ & SARS & $\begin{array}{l}\text { SARS-CoV-infected } \mathrm{C} 3^{-1-} \text { mice exhibited significantly less } \\
\text { weight loss and less respiratory dysfunction with reduced } \\
\text { lung pathology and lower cytokine and chemokine levels in } \\
\text { both the lungs and the sera }\end{array}$ & [65] \\
\hline \multicolumn{4}{|c|}{$\begin{array}{l}\text { Ace } 2^{-/-} \text {: angiotensinogen converting enzyme } 2 \text { knockout; SARS: severe acute respiratory syndrome; CoV: } \\
\text { coronavirus; } C 3^{-/-} \text {: complement } 3 \text { knockout; ARDS: acute respiratory distress syndrome; Tmprss } 2^{-/-} \text {: } \\
\text { transmembrane protease, serine } 2 \text { knockout; COVID-19: coronavirus disease } 2019 ; \text { hDPP4-Tg: human } \\
\text { dipeptidyl peptidase } 4 \text { transgene; MERS: Middle East Respiratory Syndrome; hACE-2: transgenic mice } \\
\text { bearing human ACE2; IFN: interferon. }\end{array}$} \\
\hline
\end{tabular}


ARDS is a common complication of infectious pneumonias, including those caused by the pathogenic coronaviruses SARS-CoV (SARS), SARS-CoV-2 (COVID-19) and MERS-CoV (MERS) [78, 81, 82]. Autopsy findings in patients who die of COVID-19 include diffuse alveolar damage, bronchogenic pneumonia, alveolar haemorrhage with capillary damage, and microvascular thrombosis, all of which are similarly seen in ARDS secondary to other aetiologies [79, 81, 83-87]. Although excessive host inflammatory response has been thought to drive ARDS and result in multi-organ failure [88], precise immunological features and molecular mechanisms underlying severe cases of COVID-19 are not completely understood. In vivo and cell-based studies indicated that lung injury in SARS-CoV infection is initially triggered by the viral spike protein [38]. For example, intraperitoneal administration of Spike-Fc fusion protein was sufficient to cause lung injury in mice, and Spike-Fc treatment exacerbated the severity of lung injury in acid-challenged mice. In contrast, Spike-Fc protein administration did not affect lung disease severity in ACE2 knockout mice, supportive of the concept that ACE2 plays a critical role in the initial stages of SARS-CoV-2 infection [64]. Using a non-human primate model of SARS-CoV, another group of investigators showed early administration of anti-spike IgG antibody resulted in more pronounced production of inflammatory cytokines by recruited macrophages and severe lung injury [69].

Pathologic changes of the pulmonary vasculature and the lung alveoli result in impaired gas exchange. Lungs in COVID-19 are characterised by aberrant vasodilation, arteritis, macro- and microvascular thromboses, and endothelial dysfunction which individually and collectively exacerbate ventilation-perfusion mismatch [89-92]. Lung tissues in fatal cases of both SARS-CoV and SARS-CoV-2 infections share similar molecular, immunological, and pathological signatures [79, 93-95]. As illustrated in figure 4, autopsy studies of lungs from COVID-19 patients reveal findings of diffuse alveolar damage, characterised by widespread type II pneumocyte hyperplasia, epithelial necrosis, fibrin deposition, hyaline membrane formation and inflammation $[80,83,96]$.

There is strong evidence for a role of CD4+ T-helper (Th) cells in promoting lung injury in COVID-19. Immunohistochemistry of autopsy specimens revealed increased infiltration of both CD4+ and CD8+ (cytotoxic) T-lymphocytes within the alveolar septa, with relatively few CD68+ macrophages [83, 97]. The lung parenchymal pathology is associated with highly increased production of Th1 inflammatory cytokines, including interferon (INF)- $\gamma$, interleukin (IL)-1 $\beta$ and IL-6. In addition, peripheral blood lymphopenia and a reduction in circulating CD4+ and+ CD8 T-cells are observed in COVID-19, consistent with these cells exiting the circulation as they move into the lung tissue [80, 83, 97]. In both ICU and non-ICU patients with COVID-19, Th1 cytokine concentrations positively correlated with viral loads and the severity of clinical lung injury [79]. These studies indicate that the Th1 cytokines may serve as biomarkers for predicting disease severity [79, 99] and potentially as therapeutic targets which exacerbate the disease pathology.

It has been hypothesised that the lung physiology in COVID-19 might differ from those seen in other forms of ARDS, as it has been observed that lung compliance in patients with COVID-19 may be preserved relative to the degree of hypoxaemia, as compared to other ARDS aetiologies [100]. One possible explanation for this observation is that the COVID-19 pathology might predominantly involve the pulmonary vascular endothelium rather than the alveolar epithelium. While not unique to COVID-19-triggered ARDS, this hypothesis is supported by many clinical and pathological observations: small-vessel inflammation and thrombosis on histopathology [87, 101]; higher rates of clinical venous thromboembolism; abnormal coagulation profiles as indicated by elevated D-dimer concentrations [92, 98] and thromboelastogram data [102]; endothelial ACE2 expression [47]; and endothelial SARS-CoV-2 infection [92]. Furthermore, cardiovascular comorbidities characterised by endothelial dysfunction, such as hypertension, diabetes and obesity, are also risk factors for increased mortality in COVID-19. Of note, autopsy reports have also demonstrated the presence of SARS-CoV-2 antigens in extrapulmonary organs, including the kidneys, liver, spleen, neurons and the gastrointestinal tract. It is plausible that ACE2 in the arterial and venous endothelial cells of these organs might serve as conduits for the systemic inflammatory response seen in COVID-19 [103]. Therefore, targeting endothelial ACE2 could be a potential therapeutic strategy in SARS-CoV-2 infection.

\section{Potential molecular and biochemical therapeutic targets in the host}

Given the data discussed above regarding the components of the host which facilitate viral entry, such as ACE2, and contribute to an over-exuberant immune response, such as CD4 T-cells, there are many potential candidate therapeutic targets which could be found to be effective in COVID-19. Additionally there are many targets within the virus itself, a review of which has been recently published elsewhere [104] and is outside the scope of the present review, but the combination of anti-viral and host-modulating therapeutics may prove to be especially powerful. 
The RAS pathway

As depicted in figure 1, physiologic effects of ACE inhibitors and ARBs can be complex, and the overall outcome of such interventions in the context of COVID-19 is unpredictable. ACE2 facilitates viral cell entry, but ACE2 can also have protective effects through the conversion of angiotensin-II into cardioprotective angiotensin 1-7, thereby attenuating AT1 receptor-induced pathologic downstream effects [105]. Recently, it was reported that circulating angiotensin-II levels were markedly elevated in a cohort of COVID-19 patients compared to healthy controls [34, 54], suggesting that upregulation of ACE2-mediated angiotensin 1-7 production could reduce RAS-derived multi-organ injury in these patients. It is noteworthy that clinically used ACEIs do not affect the ACE2 isoform, the substrate binding site of which demonstrates amino acid substitutions when compared to that of the ACE isoform (figure 1).

One potential therapeutic strategy targeting RAS is blocking the interaction between ACE2 and SARS-CoV-2, for example through the small molecule APN01 (Aperion Biologics, Vienna, Austria), which is a recombinant human ACE2 protein. By mimicking endogenous human ACE2 and binding SARS-CoV-2, APN01 can block viral cell entry. In addition, it can also lessen the AT1 receptor-mediated injurious inflammatory responses in the lungs, protecting from ARDS and other lung damages. APN01 was well-tolerated in patients with pulmonary arterial hypertension and ARDS, as well as in healthy volunteers in phase I and phase II clinical trials. APN01 is currently being studied in a phase II clinical trial (NCT04335136) in COVID-19 patients.

Another promising approach to inhibit the virus-host cell interaction is targeting the RBD of the SARS-CoV-2 S-protein, thereby blocking its association with pulmonary cell surface receptors like ACE2.

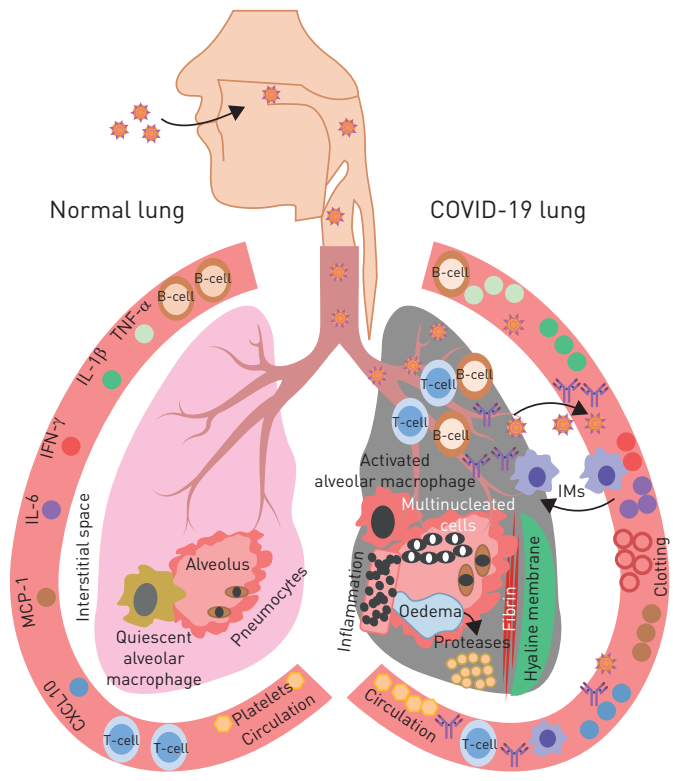

\author{
Lymphopenia 4 \\ (CD4+ T, CD8+ T, NK and B-cell number) $\downarrow$
}

Lymphocyte activation and dysfunction

Cytokine production, TNF- $\alpha$, INF- $\gamma$, IL-2 $\uparrow$

T-cells exhaustion markers

(PD-1, TIM3, NKG2A) 4

Granulocytes

Neutrophil $\uparrow$ Eosinophil $\downarrow$ Basophils $\downarrow$

Monocytes $\downarrow$

Cytokine storm $\uparrow$

Inflammatory cytokines, IL-1 $\beta$, IL-2, IL-6, IL-7.

IL-8, IL-10; G-CSF, GM-CSF, IP10, MCP1,

IFY- $\gamma$ and TNF- $\alpha$

Complement activation

(C3a, C5a, C5b-9) $\uparrow$

Antibodies

$(\lg M$ and $\lg G) \uparrow$

FIGURE 4 Overall lung pathophysiology, immune cell activation and cytokine production. Severe acute respiratory syndrome-coronavirus-2 infects the upper respiratory tract. Most of the patients ( $80 \%)$ recover with mild-to-moderate upper respiratory symptoms. In the remaining patients, the virus reaches the lower respiratory track triggering pathologic immune response. Around $6 \%$ of the patients shows very severe symptoms of acute respiratory distress syndrome and require intensive care unit admission. Autopsies of patients with coronavirus disease 2019 (COVID-19) showed clusters of severe respiratory illness, including associated features of diffuse alveolar damage, such as diffuse type II pneumocyte hyperplasia, epithelial necrosis, fibrin deposition and hyaline membrane formation $[80,83,96]$. Most patients who died of severe acute respiratory syndrome-coronavirus developed acute respiratory distress syndrome with interstitial mononuclear inflammatory infiltrates $[54,75,79,80,83,97]$. In addition, several nonspecific histological observations have also been observed that include oedema, fibrinous/proteinaceous exudates, hyperplastic pneumocytes, patchy interstitial chronic inflammation, and multinucleated giant cells with a dysregulated immune system that results in very high amounts of inflammatory cytokines [98]. PD1: programmed cell death protein-1; TIM3: T-cell immunoglobulin domain and mucin domain-3; NKG2A: killer cell lectin-like receptor subfamily C member 1; G-CSF: granulocyte-colony stimulating factor; GM-CSF: granulocyte-macrophage colony-stimulating factor; IP10: interferon inducible protein-10; MCP1: monocyte chemotactic protein 1; TNF: tumour necrosis factor; IL: interleukin; Ig: immunoglobulin; IFN: interferon; IMs: interstitial macrophages. 
Recently, the human monoclonal antibody 47D11 was shown to neutralise both SARS-CoV and SARS-CoV-2 and prevent their host cell entry by binding to a conserved epitope of the spike protein RBD in cell culture [106]. Another recent study suggested an essential role of CD147, another cell-surface protein, in facilitating SARS-CoV-2 invasion of the host cells [107]. Based on this observation, efficacy of CD147-binding meplazumab in COVID-19 is being tested in a clinical trial [108]. One limitation of these approaches is that mutation of the viral protein from evolutionary pressure may result in resistance to any one compound; something that will need to be carefully monitored during clinical studies and with clinical use if these medications are approved.

The complement system in COVID-19

The complement system is an essential component of the innate immune system $[65,75,109,110]$. The complement system is comprised of more than 30 soluble and cell surface-associated proteins, which are activated through three interconnected pathways: classical, alternative, and lectin [111]. Proteolytic cleavage of C3 by C3 convertase represents the final common pathway of the three pathways, resulting in the generation of anaphylatoxins, including $\mathrm{C} 3 \mathrm{a}, \mathrm{C} 4 \mathrm{a}, \mathrm{C} 3 \mathrm{~b}$ and $\mathrm{C} 4 \mathrm{~b}$. Nominally these complement fragments contribute to the elimination of pathogens through multiple biological processes, including opsonisation, myeloid cell activation, and B- and T-cell activation. The binding of C3b to C3 convertase generates $\mathrm{C} 5$ convertase, which in turn cleaves $\mathrm{C} 5$ to generate the terminal anaphylatoxins, $\mathrm{C} 5 \mathrm{a}$ and $\mathrm{C} 5 \mathrm{~b}$ [112]. These anaphylatoxins exacerbate inflammation resulting in cell injury $[113,114]$. In previous work on SARS-CoV infection, complement activation promoted systemic inflammation, rather than suppressing viral replication. Dysregulated complement activation has been previously associated with acute lung injury induced by other viral infections.

Similar to SARS-CoV infection, complement activation appears to be a characteristic feature of COVID-19 $[115,116]$. Recent reports of COVID-19 patients documented systemic complement activation involving multiple organs, including the lungs and the kidneys [91, 117-120]. Lung tissue from severe COVID-19 patients revealed C3a generation and C3-fragment deposition, accompanied by elevated serum C5a levels [121]. In addition, deposition of membrane attack complexes composed of complement factors C5b-9 has been seen in the renal tubules of COVID-19 patients [118]. The SARS-CoV-2 nuclear protein can activate the lectin pathway, and deposited mannose-binding lectin serine protease 2 and $\mathrm{C} 4$ were observed in the lungs of COVID-19 patients [120, 121].

The likely contribution of complement proteins to tissue injury in COVID-19 has led to therapeutic studies targeting multiple checkpoints in the complement cascade. The therapeutic potential of manipulating the complement system was previously suggested by studies of SARS-CoV and MERS. For example, SARS-CoV-infected C3 knockout mice, when compared to wildtype mice, demonstrated fewer neutrophils and inflammatory monocytes in the lungs along with lower levels of lung and serum cytokines [65]. Importantly, C3 deletion itself did not affect the viral load in the lungs. Similarly, a potential benefit of blocking complement signalling has been demonstrated in animal models of SARS-CoV-2 infection. Blockade of the C5a-C5aR axis abrogated proinflammatory cytokine expression and the pulmonary infiltration of macrophages, neutrophils and lymphocytes [121]. There are also early reports of a potential benefit from administration of anti-C5a monoclonal antibody in severe COVID-19 patients [121, 122]. Based on these data, there are ongoing studies (NCT04369469 and NCT04371367) of the C5 inhibitor ravulizumab and the anti-C5a receptor antibody avdoralimab in COVID-19 patients [123-125]. Overall, it is conceivable that targeting more proximate complement pathway targets in the upstream activation cascades (e.g. C3 or C4) may lead to more deleterious off-target consequences by attenuating the virus-eliminating effects of the complement system, while intervening at more terminal anaphylatoxins like $\mathrm{C} 5 \mathrm{a}-\mathrm{C} 5 \mathrm{aR}$ may result in a more favourable and effective treatment strategy.

Targeting inflammatory cells and cytokines in COVID-19

Immune dysregulation and excessive inflammatory cytokine production are implicated in COVID-19-induced ARDS and multi-organ injury [88]. Biopsy reports of severe COVID-19 patients have shown T-cell and myeloid cell infiltration in the lungs and other organs such as the kidneys, heart, spleen and lymph nodes $[97,98,118,126]$. There is also excessive activation of pro-inflammatory airway macrophages resulting in increased proinflammatory cytokines including IL-6 and tumour necrosis factor- $\alpha$ [127]. Higher levels of serum chemokines including CCL2 and CCL3 further points to recruitment of bone marrow-derived macrophages to the lungs [127]. The exact molecular mechanisms underlying pathologic immune cell activation and cytokine production in COVID-19, however, are not well understood.

One possible mechanism could be impaired type I IFN production in severe COVID-19 [9, 128]. IFNs are expressed by multiple immune cells, and in SARS and MERS they negatively regulate the activation and 
infiltration of alveolar and monocyte-derived macrophages into the lungs [129-131]. Reduced systemic IFN production has been observed in more severe cases of COVID-19 [128]. Therefore, an early intervention which augments IFN signalling, such as by administration of recombinant IFN, might be useful in mitigating the virus-mediated inflammatory response. Blockade of IFN receptor in a SARS-CoV-2 mouse model did not attenuate viral replication [5], however, suggesting the ability of the SARS-CoV-2 virus to evade immune cell-mediated opsonisation by suppressing IFN-mediated signalling pathways through currently unknown mechanisms.

Multiple ongoing trials are focusing on blocking inflammatory cytokines including using small molecules, antibodies, or cell-based approaches to reduce endothelial cell activation and injury. These approaches may focus on many pathways simultaneously, or be precisely focused on single molecules. As in other inflammatory diseases, multiple immune pathways are simultaneously activated in COVID-19, and therefore therapeutically targeting one particular pathway may or may not produce a clinically desirable benefit.

One broad approach is the administration of mesenchymal stem cells (MSCs), which are well-known immuno-modulators that have been shown to alleviate lung injury and enhance lung repair in preclinical models of ARDS, and in early clinical trials of patients with inflammatory lung diseases [132, 133]. In a phase II clinical trial (NCT02097641), a single dose of intravenous bone-marrow-derived MSC administration was both safe and efficacious in patients with moderate-to severe non-COVID-19 ARDS [134]. This therapy could be similarly effective in COVID-19 patients as demonstrated in a recent case series of severe COVID-19 patients $[135,136]$. This approach has led to the now-ongoing STAT trial of MSCs in ARDS (NCT03818854), which while not focused on COVID-19 a priori is presently enrolling many COVID-19 subjects due to the current preponderance of this disease.

Just as important as uncovering individual therapeutic targets is testing the efficacy of combination therapies, which simultaneously target multiple arms of the immune system or combine anti-viral with host modulating treatments. One example is a clinical trial (NCT04409262) studying the concurrent administration of the anti-viral remdesivir with the IL- 6 receptor inhibitor tocilizumab, targeting the virus and the host immune response together. Other examples are the combinations of lopinavir/ritonavir, ribavirin and IFN- $\beta-1 \mathrm{~b}$, or of IFN- $\beta-1 \mathrm{a}$ and remdesivir are being tested (NCT04276688 and NCT04492475).

Ongoing pre-clinical studies and the results of these clinical trials will help address important questions regarding the role of immune cells in COVID-19 pathogenesis: Which subset(s) of myeloid cells take up SARS-CoV2 antigens? Which antigen-presenting cells are responsible for T-cell antigen recognition in the lymph nodes? Differentiation into which subsets of T-cells is induced by antigen presentation? Which cytokines trigger bone marrow production of inflammatory monocytes and what are the mechanisms underlying their recruitment to the lungs and other organs? How do these immune cells trigger injury of the lungs and other organs in COVID-19? As these questions are answered through mechanistic studies utilising animal models of SARS-CoV-2 infection and clinical trials, therapeutic approaches will be refined and promising combination therapies will be identified.

\section{Balancing type 1 and type 2 immunity in COVID-19}

It is well established that during viral infections, cells of the innate immune system recognise viral replication intermediates and secrete pro-inflammatory cytokines, contributing to tissue damage [137]. Virus-derived antigens are taken up by antigen-presenting cells and carried to local draining lymph nodes [137]. Depending on the local cytokine milieu in the draining lymph node, CD4+ T-cell stimulation by antigen presenting cells induce different types of Th adaptive cell responses. There is a critical balance between an anti-viral innate response crucial to eliminate the invading virus, versus a robust and persistent immune response damaging host tissues. Related to this is an unbalanced adaptive immune response, marked by lower percentages and absolute counts of CD3+, CD4+ and CD8+ lymphocyte populations associated with worse organ injury and COVID-19 related mortality [138]. The exact contributions of Th1 versus Th2 immunity to viral clearance or host tissue injury is not clear in COVID-19. Severe COVID-19 is characterised by a "cytokine storm" which has features predominantly of Th1, including elevated concentrations of IL-2, IL-7, IL-12, granulocyte-colony stimulating factor, IFN inducible protein-10, monocyte chemotactic protein-1, macrophage inflammatory protein- $1 \alpha$, tumour necrosis factor- $\alpha$, and IFN- $\gamma[68,80,83,97,128,139]$. Interestingly, similar patterns have been observed in other respiratory viral infections, with predominant features of Th1 cell and cytokines, accompanied by suppression of Th2 immunity [140-143].

Considering that there is a mutually antagonistic balance between Th1 and Th2, with viral induced Th1 immunity blunting Th2 immunity, it may be that promoting a Th2 immune response either prior to or 
during early infection might suppress the robust and potentially excessive Th1 derived inflammatory response triggered by SARS-CoV-2. This approach has worked with other viral infections such as rhinovirus, respiratory syncytial virus, or influenza A virus, when animals which have biased immune systems that promote a type 2 immune response were found to have less severe disease than wildtype or type 1-biased animals [143-149].

In COVID-19, the equivalent natural experiment will be to observe the outcomes in patients who have chronic, comorbid conditions which drive Th2 immunity, such as type 2 asthma or concurrent parasitic infections. For example, it may be observed that patients with pre-existing type 2 inflammatory conditions are more susceptible to the initial stages of viral replication due to blunted anti-viral type 1 immunity, but may be relatively protected from later excessive inflammatory complications of COVID-19 such as severe ARDS. Importantly, recent studies found that asthma does not appear to be a significant comorbidity for patients hospitalised with severe COVID-19, and asthma does not increase risk for mechanical ventilation $[150,151]$. It would be interesting to see how individuals with Th2-dominated parasitic infections like schistosomiasis $[152,153]$ respond following SARS-CoV-2 infection.

Promoting type 2 immunity such as administering recombinant type 2 cytokines could be a therapeutic approach. For example, IL-13 has been shown to downregulate ACE2 expression in airway epithelial cells [154], which may reduce viral entry and excessive production of Th1 cytokines that are detrimental to the cells. An alternative approach would be administration of non-infectious compounds which promote type 2 immunity, or even auto-transfusion of CD4 T-cells that were biased ex vivo to a Th2 phenotype, such as through sensitisation to ovalbumin or Schistosoma egg antigen; approaches which could deliver the benefits of type 2 inflammation without long-term complications associated with chronic asthma or parasitic infections.

\section{Genetic association studies can help guide therapeutic development}

The heterogeneity of COVID-19 pathology suggests genetic polymorphisms may contribute to specific immune phenotypes and ultimately the severity and outcome of SARS-CoV-2 infection [155]. Of note, several single nucleotide polymorphisms within genes in the RAS pathway, including the ACE2 gene, have been previously linked to cardiovascular diseases [105, 156-158]. RAS polymorphisms are also associated with pharmacodynamic differences between individuals treated with ACE inhibitors or ARBs [159]. As examples, synonymous and non-synonymous single nucleotide polymorphisms in pro-inflammatory genes

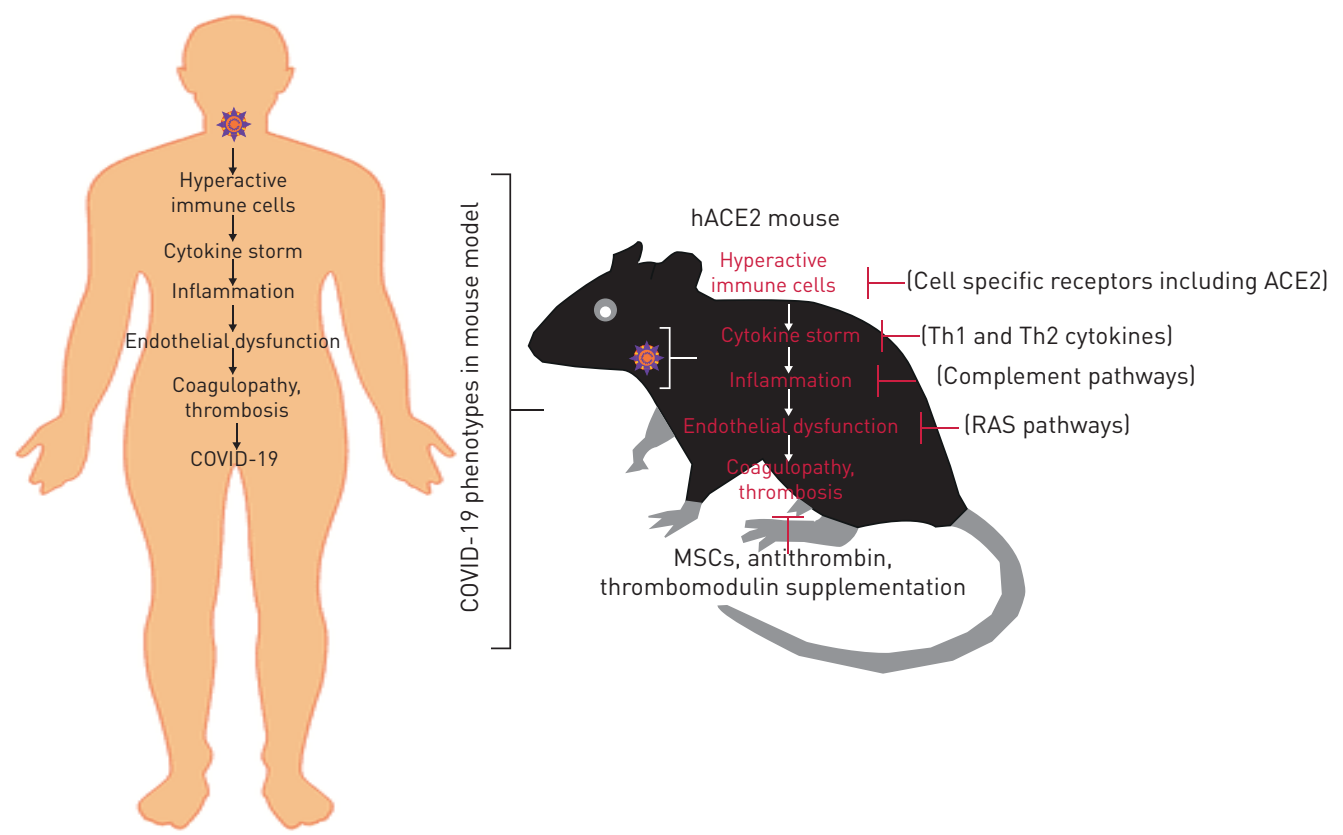

FIGURE 5 Schematic summary of the potential therapeutic targets. Recapitulation of coronavirus disease 2019 (COVID-19) pathological conditions in global or cell-specific knockouts in the humanised angiotensin-converting enzyme (hACE2) mouse model will enable investigators to dissect the inflammatory immune cascades that are involved in disease pathology. As shown, the blockade of cell-specific receptors, T-helper (Th)1 and/or Th2 cytokines, complement activation, renin-angiotensin system pathway activity, administration of mesenchymal stem cells, and antithrombotic treatments could all be useful as therapeutic targets in COVID-19. 
including CXCL10/IFN-inducible protein-10, heme oxygenase 1, IL-1 $\alpha$, IL-18, FGL2, and leukocyte antigen class I and II have been associated with either infection, severity or nasopharyngeal SARS-CoV viral shedding [160-164]. Genetic studies which identify risk factors for SARS-CoV-2 infection or COVD-19 pathology in relation to host-pathogen interactions and inter-individual disease phenotypes will help identify at-risk populations, host factors which can be targeted to modulate the disease phenotype, and even potentially novel therapeutic approaches which may be personalised to patients with specific genotypes.

\section{Conclusions}

Effective treatments for COVID-19 are urgently needed as respiratory SARS-CoV-2 infection is a devastating condition which is not yet effectively treated. This viral infection represents a unique challenge to the host immune system, but at the same time is a unique opportunity to identify precise therapeutic approaches to this infection and host pathology resulting from a single agent. Herein, we have discussed three major challenges to developing effective treatments against COVID-19: 1) the incomplete understanding of the disease pathogenesis; 2) the versatile functions of the virus receptor ACE2; and 3) the delicate balance between the virus-eliminating and the lung-injuring effects of the host inflammatory response. Discovery of new, effective and safe treatments will follow selection of appropriate therapeutic targets based on human lung histopathology and conduct of mechanistic studies utilising animal models, followed by appropriate clinical trials (figure 5).

Conflict of interest: R. Kumar reports grants from the American Heart Association and the ATS Foundation/Pulmonary Hypertension Association during the conduct of the study. M.H. Lee has nothing to disclose. C. Mickael has nothing to disclose. B. Kassa has nothing to disclose. Q. Pasha has nothing to disclose. R. Tuder has nothing to disclose. B. Graham reports grants from the National Institutes of Health during the conduct of the study.

Support statement: R. Kumar avails the American Heart Association Grant (19CDA34730030) and ATS Foundation/ Pulmonary Hypertension Association Research Fellowship; B. Graham avails NIH grant R01HL135872; R. Tuder and B. Graham avail NIH grant P01HL014985; and C. Mickael, R. Tuder and B. Graham avail NIH grant P01HL152961. Funding information for this article has been deposited with the Crossref Funder Registry.

\section{References}

1 World Health Organization. WHO Coronavirus Disease (COVID-19) Dashboard. https://covid19.who.int Date last updated: 11 November 2020; date last accessed: 7 September 2020.

2 World Health Organization. Summary of probable SARS cases with onset of illness from 1 November 2002 to 31 July 2003. www.who.int/csr/sars/country/table2004_04_21/en/ Date last updated: 24 July 2015; date last accessed: 7June 2020.

3 Hamming I, Timens W, Bulthuis M, et al. Tissue distribution of ACE2 protein, the functional receptor for SARS coronavirus. A first step in understanding SARS pathogenesis. J Pathol 2004; 203: 631-637.

4 Florindo HF, Kleiner R, Vaskovich-Koubi D, et al. Immune-mediated approaches against COVID-19. Nat Nanotechnol 2020; 15: 630-645.

5 Israelow B, Song E, Mao T, et al. Mouse model of SARS-CoV-2 reveals inflammatory role of type I interferon signaling. J Exp Med 2020; 217: e20201241.

6 Bao L, Deng W, Huang B, et al. The pathogenicity of SARS-CoV-2 in hACE2 transgenic mice. Nature 2020; 583: 830-833.

7 Jiang R-D, Liu M-Q, Chen $\mathrm{Y}$, et al. Pathogenesis of SARS-CoV-2 in transgenic mice expressing human angiotensin-converting enzyme 2. Cell 2020; 182: 50-58.

8 Sia SF, Yan L-M, Chin AWH, et al. Pathogenesis and transmission of SARS-CoV-2 in golden hamsters. Nature 2020; 583: 834-838.

9 Blanco-Melo D, Nilsson-Payant BE, Liu W-C, et al. Imbalanced host response to SARS-CoV-2 drives development of COVID-19. Cell 2020; 181: 1036-1045.

10 Rockx B, Kuiken T, Herfst S, et al. Comparative pathogenesis of COVID-19, MERS, and SARS in a nonhuman primate model. Science 2020; 368: 1012-1015.

11 Belouzard S, Millet JK, Licitra BN, et al. Mechanisms of coronavirus cell entry mediated by the viral spike protein. Viruses 2012; 4: 1011-1033.

12 Wu A, Peng Y, Huang B, et al. Genome composition and divergence of the novel coronavirus (2019-nCoV) originating in China. Cell Host Microbe 2020; 27: 325-328.

13 Andersen KG, Rambaut A, Lipkin WI, et al. The proximal origin of SARS-CoV-2. Nat Med 2020; 26: 450-452.

14 Chan JF-W, Kok K-H, Zhu Z, et al. Genomic characterization of the 2019 novel human-pathogenic coronavirus isolated from a patient with atypical pneumonia after visiting Wuhan. Emerg Microbes Infect 2020; 9: 221-236.

15 Lam TT-Y, Jia N, Zhang Y-W, et al. Identifying SARS-CoV-2-related coronaviruses in Malayan pangolins. Nature 2020; 583: 282-285

16 Zhang T, Wu Q, Zhang Z. Probable pangolin origin of SARS-CoV-2 associated with the COVID-19 outbreak. Curr Biol 2020; 30: 1346-1351.

17 Wan Y, Shang J, Graham R, et al. Receptor recognition by the novel coronavirus from Wuhan: an analysis based on decade-long structural studies of SARS coronavirus. J Virol 2020; 94: e00127-20.

18 Centers for Disease Control and Prevention. Coronavirus Disease 2019 (COVID-19). Frequently asked questions. www.cdc.gov/coronavirus/2019-ncov/faq.html. Date last updated: 8 November 2020; date last accessed: 18 April 2020. 
Ge X-Y, Li J-L, Yang X-L, et al. Isolation and characterization of a bat SARS-like coronavirus that uses the ACE2 receptor. Nature 2013; 503: 535-538.

Zhong J, Basu R, Guo D, et al. Angiotensin-converting enzyme 2 suppresses pathological hypertrophy, myocardial fibrosis, and cardiac dysfunction. Circulation 2010; 122: 717-728.

Zhong J, Guo D, Chen CB, et al. Prevention of angiotensin II-mediated renal oxidative stress, inflammation, and fibrosis by angiotensin-converting enzyme 2. Hypertension 2011; 57: 314-322.

Walls AC, Park Y-J, Tortorici MA, et al. Structure, function, and antigenicity of the SARS-CoV-2 spike glycoprotein. Cell 2020; 181: 281-292.

Breitling S, Krauszman A, Parihar R, et al. Dose-dependent, therapeutic potential of angiotensin-(1-7) for the treatment of pulmonary arterial hypertension. Pulm Circ 2015; 5: 649-657.

de Man FS, Tu L, Handoko ML, et al. Dysregulated renin-angiotensin-aldosterone system contributes to pulmonary arterial hypertension. Am J Respir Crit Care Med 2012; 186: 780-789.

Morrell NW, Atochina EN, Morris KG, et al. Angiotensin converting enzyme expression is increased in small pulmonary arteries of rats with hypoxia-induced pulmonary hypertension. J Clin Invest 1995; 96: 1823-1833.

Dai H, Jiang L, Xiao Z, et al. ACE2-angiotensin-(1-7)-Mas axis might be a promising therapeutic target for pulmonary arterial hypertension. Nat Rev Cardiol 2015; 12: 374.

Wrapp D, Wang N, Corbett KS, et al. Cryo-EM structure of the 2019-nCoV spike in the prefusion conformation. Science 2020; 367: 1260-1263.

Bradford CN, Ely DR, Raizada MK. Targeting the vasoprotective axis of the renin-angiotensin system: a novel strategic approach to pulmonary hypertensive therapy. Curr Hypertens Rep 2010; 12: 212-219.

Shenoy V, Qi Y, Katovich MJ, et al. ACE2, a promising therapeutic target for pulmonary hypertension. Curr Opin Pharmacol 2011; 11: 150-155.

Lai ZW, Hanchapola I, Steer DL, et al. Angiotensin-converting enzyme 2 ectodomain shedding cleavage-site identification: determinants and constraints. Biochemistry 2011; 50: 5182-5194.

Jia HP, Look DC, Tan P, et al. Ectodomain shedding of angiotensin converting enzyme 2 in human airway epithelia. Am J Physiol Lung Cell Mol Physiol 2009; 297: L84-L96.

Lin Q, Keller RS, Weaver B, et al. Interaction of ACE2 and integrin $\beta 1$ in failing human heart. Biochim Biophys Acta 2004; 1689: 175-178.

Iwata-Yoshikawa N, Okamura T, Shimizu Y, et al. TMPRSS2 contributes to virus spread and immunopathology in the airways of murine models after coronavirus infection. J Virol 2019; 93: e01815-18.

Wang K, Gheblawi M, Oudit GY. Angiotensin Converting Enzyme 2: A Double-Edged Sword. Circulation 2020; 142: 426-428.

Zhou P, Yang X-L, Wang X-G, et al. A pneumonia outbreak associated with a new coronavirus of probable bat origin. Nature 2020; 579: 270-273.

Yan R, Zhang Y, Li Y, et al. Structural basis for the recognition of SARS-CoV-2 by full-length human ACE2. Science 2020; 367: 1444-1448.

Shang J, Ye G, Shi K, et al. Structural basis of receptor recognition by SARS-CoV-2. Nature 2020; 581: 221-224

Li W, Moore MJ, Vasilieva N, et al. Angiotensin-converting enzyme 2 is a functional receptor for the SARS coronavirus. Nature 2003; 426: 450-454.

Hoffmann M, Kleine-Weber H, Schroeder S, et al SARS-CoV-2 cell entry depends on ACE2 and TMPRSS2 and is blocked by a clinically proven protease inhibitor. Cell 2020; 181: 271-280.e8.

Glowacka I, Bertram S, Müller MA, et al. Evidence that TMPRSS2 activates the severe acute respiratory syndrome coronavirus spike protein for membrane fusion and reduces viral control by the humoral immune response. J Virol 2011; 85: 4122-4134.

Matsuyama S, Nagata $\mathrm{N}$, Shirato $\mathrm{K}$, et al. Efficient activation of the severe acute respiratory syndrome coronavirus spike protein by the transmembrane protease TMPRSS2. J Virol 2010; 84: 12658-12664.

Shulla A, Heald-Sargent T, Subramanya G, et al. A transmembrane serine protease is linked to the severe acute respiratory syndrome coronavirus receptor and activates virus entry. J Virol 2011; 85: 873-882.

da Silva JS, Gabriel-Costa D, Wang H, et al. Blunting of cardioprotective actions of estrogen in female rodent heart linked to altered expression of cardiac tissue chymase and ACE2. J Renin Angiotensin Aldosterone Syst 2017; 18: 1470320317722270.

Guan W-J, Ni Z-Y, Hu Y, et al. Clinical characteristics of coronavirus disease 2019 in China. N Engl J Med 2020; 382: 1708-1720.

Yang X, Yu Y, Xu J, et al. Clinical course and outcomes of critically ill patients with SARS-CoV-2 pneumonia in Wuhan, China: a single-centered, retrospective, observational study. Lancet Respir Med 2020; 8: 475-481.

Zhang J-J, Dong X, Cao Y-Y, et al. Clinical characteristics of 140 patients infected with SARS-CoV-2 in Wuhan, China. Allergy 2020; 75: 1730-1741.

Ferrario CM, Jessup J, Chappell MC, et al. Effect of angiotensin-converting enzyme inhibition and angiotensin II receptor blockers on cardiac angiotensin-converting enzyme 2. Circulation 2005; 111: 2605-2610.

Gheblawi M, Wang K, Viveiros A, et al. Angiotensin-converting enzyme 2: SARS-CoV-2 receptor and regulator of the renin-angiotensin system: celebrating the 20th anniversary of the discovery of ACE2. Circ Res 2020; 126: $1456-1474$.

Gurwitz D. Angiotensin receptor blockers as tentative SARS-CoV-2 therapeutics. Drug Dev Res 2020; 81: 537-540.

Rico-Mesa JS, White A, Anderson AS. Outcomes in patients with COVID-19 infection taking ACEI/ARB. Curr Cardiol Rep 2020; 22: 31.

Li XC, Zhang J, Zhuo JL. The vasoprotective axes of the renin-angiotensin system: physiological relevance and therapeutic implications in cardiovascular, hypertensive and kidney diseases. Pharmacol Res 2017; 125: 21-38.

Sun ML, Yang JM, Sun YP, et al. [Inhibitors of RAS might be a good choice for the therapy of COVID-19 pneumonia]. Zhonghua Jie He He Hu Xi Za Zhi 2020; 43: 219-222.

Imai Y, Kuba K, Rao S, et al. Angiotensin-converting enzyme 2 protects from severe acute lung failure. Nature 2005; 436: 112-116.

Liu Y, Yang Y, Zhang C, et al. Clinical and biochemical indexes from 2019-nCoV infected patients linked to viral loads and lung injury. Sci China Life Sci 2020; 63: 364-374. 
Reddy R, Asante I, Liu S, et al. Circulating angiotensin peptides levels in acute respiratory distress syndrome correlate with clinical outcomes: a pilot study. PLoS One 2019; 14: e0213096.

Imai Y, Kuba K, Penninger JM. The discovery of angiotensin-converting enzyme 2 and its role in acute lung injury in mice. Exp Physiol 2008; 93: 543-548.

Li G, He X, Zhang L, et al. Assessing ACE2 expression patterns in lung tissues in the pathogenesis of COVID-19. J Autoimmun 2020; 112: 102463.

Peng YD, Meng K, Guan HQ, et al. [Clinical characteristics and outcomes of 112 cardiovascular disease patients infected by 2019-nCoV]. Zhonghua Xin Xue Guan Bing Za Zhi 2020; 48: E004.

Vaduganathan M, Vardeny O, Michel T, et al. Renin-angiotensin-aldosterone system inhibitors in patients with Covid-19. N Engl J Med 2020; 382: 1653-1659.

Roberts A, Deming D, Paddock CD, et al. A mouse-adapted SARS-coronavirus causes disease and mortality in BALB/c mice. PLoS Pathog 2007; 3: e5.

Day CW, Baric R, Cai SX, et al. A new mouse-adapted strain of SARS-CoV as a lethal model for evaluating antiviral agents in vitro and in vivo. Virology 2009; 395: 210-222.

Zhao J, Li K, Wohlford-Lenane $\mathrm{C}$, et al. Rapid generation of a mouse model for Middle East respiratory syndrome. Proc Natl Acad Sci U S A 2014; 111: 4970-4975.

Wang X, Dhindsa R, Povysil G, et al. Transcriptional inhibition of host viral entry proteins as a therapeutic strategy for SARS-CoV-2. Preprints 2020; 2020030360 [https://doi.org/10.20944/preprints202003.0360.v1].

coronavirus-induced lung injury. Nat Med 2005; 11: 875-879. Gralinski LE, Sheahan TP, Morrison TE, et al. Complement activation contributes to severe acute respiratory syndrome coronavirus pathogenesis. mBio 2018; 9: e01753-18.

Dinnon KH, Leist SR, Schäfer A, et al. A mouse-adapted model of SARS-CoV-2 to test COVID-19 countermeasures. Nature 2020; 586: 560-566.

Letko M, Marzi A, Munster V. Functional assessment of cell entry and receptor usage for SARS-CoV-2 and other lineage B betacoronaviruses. Nat Microbiol 2020; 5: 562-569.

Chan JF-W, Zhang AJ, Yuan S, et al. Simulation of the clinical and pathological manifestations of coronavirus disease 2019 (COVID-19) in golden Syrian hamster model: implications for disease pathogenesis and transmissibility. Clin Infect Dis 2020: in press [http://doi.org/10.1093/cid/ciaa325].

Liu L, Wei Q, Lin Q, et al. Anti-spike IgG causes severe acute lung injury by skewing macrophage responses during acute SARS-CoV infection. JCI Insight 2019; 4: e123158.

Zhang L, Zhang F, Yu W, et al. Antibody responses against SARS coronavirus are correlated with disease outcome of infected individuals. J Med Virol 2006; 78: 1-8.

Smits SL, de Lang A, van den Brand JMA, et al. Exacerbated innate host response to SARS-CoV in aged non-human primates. PLoS Pathog 2010; 6: e1000756.

Haagmans BL, Kuiken T, Martina BE, et al. Pegylated interferon-alpha protects type 1 pneumocytes against SARS coronavirus infection in macaques. Nat Med 2004; 10: 290-293.

Rockx B, Feldmann F, Brining D, et al. Comparative pathogenesis of three human and zoonotic SARS-CoV strains in cynomolgus macaques. PLoS One 2011; 6: e18558.

Zou L, Ruan F, Huang M, et al. SARS-CoV-2 viral load in upper respiratory specimens of infected patients. N Engl J Med 2020; 382: 1177-1179.

Peiris J, Chu C, Cheng V, et al. Clinical progression and viral load in a community outbreak of coronavirus-associated SARS pneumonia: a prospective study. Lancet 2003; 361: 1767-1772.

Yu J, Tostanoski LH, Peter L, et al. DNA vaccine protection against SARS-CoV-2 in rhesus macaques. Science 2020; 369: 806-811.

$\mathrm{Xu} \mathrm{A}, \mathrm{Ma} \mathrm{J}$, Guo X, et al. Association of a province-wide intervention with salt intake and hypertension in Shandong Province, China, 2011-2016. JAMA Intern Med 2020; 180: 877-886. coronavirus pneumonia in Wuhan, China: a descriptive study. Lancet 2020; 395: 507-513. China. Lancet 2020; 395: 497-506. postmortem core biopsies. Mod Pathol 2020; 33: 1007-1014.

Wang $\mathrm{D}, \mathrm{Hu} \mathrm{B}, \mathrm{Hu} \mathrm{C}$, et al. Clinical characteristics of 138 hospitalized patients with 2019 novel coronavirus-infected pneumonia in Wuhan, China. JAMA 2020; 323: 1061-1069.

Zhu Z, Lian X, Su X, et al. From SARS and MERS to COVID-19: a brief summary and comparison of severe acute respiratory infections caused by three highly pathogenic human coronaviruses. Respir Res 2020; 21: 224 .

Barton LM, Duval EJ, Stroberg E, et al. COVID-19 autopsies, Oklahoma, USA. Am J Clin Pathol 2020; 153: 725-733.

Bikdeli B, Madhavan MV, Jimenez D, et al. COVID-19 and thrombotic or thromboembolic disease: implications for prevention, antithrombotic therapy, and follow-up: JACC State-of-the-Art Review. J Am Coll Cardiol 2020; 75: 2950-2973.

Hanley B, Lucas SB, Youd E, et al. Autopsy in suspected COVID-19 cases. J Clin Pathol 2020; 73: 239-242.

Schaller T, Hirschbühl K, Burkhardt K, et al. Postmortem examination of patients with COVID-19. JAMA 2020; 323: 2518-2520.

Zhou F, Yu T, Du R, et al. Clinical course and risk factors for mortality of adult inpatients with COVID-19 in Wuhan, China: a retrospective cohort study. Lancet 2020; 395: 1054-1062.

Mehta P, McAuley DF, Brown M, et al. COVID-19: consider cytokine storm syndromes and immunosuppression. Lancet 2020; 395: 1033-1034.

Kobayashi J, Murata I. Nitric oxide inhalation as an interventional rescue therapy for COVID-19-induced acute respiratory distress syndrome. Ann Intensive Care 2020; 10: 61.

England JT, Abdulla A, Biggs CM, et al. Weathering the COVID-19 storm: Lessons from hematologic cytokine syndromes. Blood Rev 2020: in press [https://doi.org/10.1016/j.blre.2020.100707]. 
91 Magro C, Mulvey JJ, Berlin D, et al. Complement associated microvascular injury and thrombosis in the pathogenesis of severe COVID-19 infection: a report of five cases. Transl Res 2020; 220: 1-13.

92 Varga Z, Flammer AJ, Steiger P, et al. Endothelial cell infection and endotheliitis in COVID-19. Lancet 2020; 395: 1417-1418.

93 Wu F, Zhao S, Yu B, et al. A new coronavirus associated with human respiratory disease in China. Nature 2020; 579: 265-269.

94 Drosten C, Günther S, Preiser W, et al. Identification of a novel coronavirus in patients with severe acute respiratory syndrome. $N$ Engl J Med 2003; 348: 1967-1976.

95 Ksiazek TG, Erdman D, Goldsmith CS, et al. A novel coronavirus associated with severe acute respiratory syndrome. N Engl J Med 2003; 348: 1953-1966.

96 Nicholls J, Dong X-P, Jiang G, et al. SARS: clinical virology and pathogenesis. Respirology 2003; 8: Suppl., S6-S8.

97 Xu Z, Shi L, Wang Y, et al. Pathological findings of COVID-19 associated with acute respiratory distress syndrome. Lancet Respir Med 2020; 8: 420-422.

98 Merad M, Martin JC. Pathological inflammation in patients with COVID-19: a key role for monocytes and macrophages. Nat Rev Immunol 2020; 20: 355-362.

99 Liu Y, Zhang C, Huang F, et al. Elevated plasma levels of selective cytokines in COVID-19 patients reflect viral load and lung injury. Natl Sci Rev 2020; 7: 1003-1011.

100 Gattinoni L, Coppola S, Cressoni M, et al. COVID-19 does not lead to a "typical" acute respiratory distress syndrome. Am J Respir Crit Care Med 2020; 201: 1299-1300.

101 Klok FA, Kruip MJHA, van der Meer NJM, et al. Confirmation of the high cumulative incidence of thrombotic complications in critically ill ICU patients with COVID-19: an updated analysis. Thromb Res 2020; 191: 148-150.

102 Panigada M, Bottino N, Tagliabue P, et al. Hypercoagulability of COVID-19 patients in intensive care unit: a report of thromboelastography findings and other parameters of hemostasis. J Thromb Haemost 2020; 18: $1738-1742$.

103 Huertas A, Montani D, Savale L, et al. Endothelial cell dysfunction: a major player in SARS-CoV-2 infection (COVID-19)? Eur Respir J 2020; 56: 2001634.

104 Poduri R, Joshi G, Jagadeesh G. Drugs targeting various stages of the SARS-CoV-2 life cycle: exploring promising drugs for the treatment of Covid-19. Cell Signal 2020; 74: 109721.

105 Wang D, Chai X, Magnussen CG, et al. Renin-angiotensin-system, a potential pharmacological candidate, in acute respiratory distress syndrome during mechanical ventilation. Pulm Pharmacol Ther 2019; $58: 101833$.

106 Wang C, Li W, Drabek D, et al. Publisher correction: a human monoclonal antibody blocking SARS-CoV-2 infection. Nat Commun 2020; 11: 2511.

107 Wang K, Chen W, Zhou Y-S, et al. SARS-CoV-2 invades host cells via a novel route: CD147-spike protein BioRxiv 2020; preprint [https://doi.org/10.1101/2020.03.14.988345].

108 Bian H, Zheng Z-H, Wei D, et al. Meplazumab treats COVID-19 pneumonia: an open-labelled, concurrent controlled add-on clinical trial. medRxiv 2020; preprint [https://doi.org/10.1101/2020.03.21.20040691]

109 Mathern DR, Heeger PS. Molecules great and small: the complement system. Clin J Am Soc Nephrol 2015; 10: $1636-1650$.

110 Sun S, Zhao G, Liu C, et al. Inhibition of complement activation alleviates acute lung injury induced by highly pathogenic avian influenza H5N1 virus infection. Am J Respir Cell Mol Biol 2013; 49: 221-230.

111 Wills-Karp M. Complement activation pathways: a bridge between innate and adaptive immune responses in asthma. Proc Am Thorac Soc 2007; 4: 247-251.

112 Wang R, Xiao H, Guo R, et al. The role of C5a in acute lung injury induced by highly pathogenic viral infections. Emerg Microbes Infect 2015; 4: e28.

113 Buras JA, Rice L, Orlow D, et al. Inhibition of C5 or absence of C6 protects from sepsis mortality. Immunobiology 2004; 209: 629-635.

114 Huber-Lang M, Sarma VJ, Lu KT, et al. Role of C5a in multiorgan failure during sepsis. J Immunol 2001; 166 1193-1199.

115 Chen J-H, Chang Y-W, Yao C-W, et al. Plasma proteome of severe acute respiratory syndrome analyzed by two-dimensional gel electrophoresis and mass spectrometry. Proc Natl Acad Sci U S A 2004; 101: 17039-17044.

116 Pang RTK, Poon TCW, Chan KCA, et al. Serum proteomic fingerprints of adult patients with severe acute respiratory syndrome. Clin Chem 2006; 52: 421-429.

117 Batlle D, Soler MJ, Sparks MA, et al. Acute kidney injury in COVID-19: emerging evidence of a distinct pathophysiology. J Am Soc Nephrol 2020; 31: 1380-1383.

118 Diao B, Wang C, Wang R, et al. Human Kidney is a Target for Novel Severe Acute Respiratory Syndrome Coronavirus 2 (SARS-CoV-2) Infection. medRxiv 2020; preprint [https://doi.org/10.1101/2020.03.04.20031120].

119 Noris M, Benigni A, Remuzzi G. The case of complement activation in COVID-19 multiorgan impact. Kidney Int 2020; 98: 314-322.

120 Risitano AM, Mastellos DC, Huber-Lang M, et al. Author correction: Complement as a target in COVID-19? Nat Rev Immunol 2020; 20: 448.

121 Gao $\mathrm{T}$, $\mathrm{Hu} \mathrm{M}$, Zhang $\mathrm{X}$, et al. Highly pathogenic coronavirus $\mathrm{N}$ protein aggravates lung injury by MASP-2-mediated complement over-activation. medRxiv 2020; preprint [https://doi.org/10.1101/2020.03.29. 20041962].

122 Uckun FM. Reducing the fatality rate of COVID-19 by applying clinical insights from immuno-oncology and lung transplantation. Front Pharmacol 2020; 11: 796.

123 Alexion Pharmaceuticals. SOLIRIS ${ }^{\star}$ (Eculizumab) for the Treatment of Participants With Coronavirus Disease 2019 (COVID 19). NCT04355494 https://clinicaltrials.gov/ct2/show/NCT04355494 Date last updated: 18 August 2020; date last accessed: 18 August 2020.

124 Alexion Pharmaceuticals. Efficacy and Safety Study of IV Ravulizumab in Patients With COVID-19 Severe Pneumonia. NCT04369469 https://clinicaltrials.gov/ct2/show/NCT04369469 Date last updated: 8 October 2020; date last accessed: 16 November 2020.

125 Assistance Publique - Hôpitaux de Paris. CORIMUNO19-ECU: Trial Evaluating Efficacy and Safety of Eculizumab (Soliris) in Patients With COVID-19 Infection, Nested in the CORIMUNO-19 Cohort. 
NCT04346797 https://clinicaltrials.gov/ct2/show/NCT04346797 Date last updated: 27 April 2020; date last accessed: 27 April 2020.

126 Chen Y, Feng Z, Diao B, et al. The novel severe acute respiratory syndrome coronavirus 2 (SARS-CoV-2) directly decimates human spleens and lymph nodes. medRxiv 2020; preprint [https://doi.org/10.1101/2020.03.27. 20045427].

127 Catanzaro M, Fagiani F, Racchi M, et al. Immune response in COVID-19: addressing a pharmacological challenge by targeting pathways triggered by SARS-CoV-2. Signal Transduct Target Ther 2020; 5: 84.

128 Hadjadj J, Yatim N, Barnabei L, et al. Impaired type I interferon activity and inflammatory responses in severe COVID-19 patients. Science 2020; 369: 718-724.

129 Channappanavar R, Fehr AR, Vijay R, et al. Dysregulated type I interferon and inflammatory monocyte-macrophage responses cause lethal pneumonia in SARS-CoV-infected mice. Cell Host Microbe 2016; 19: 181-193.

130 Cong Y, Hart BJ, Gross R, et al. MERS-CoV pathogenesis and antiviral efficacy of licensed drugs in human monocyte-derived antigen-presenting cells. PLoS One 2018; 13: e0194868.

131 Page C, Goicochea L, Matthews K, et al. Induction of alternatively activated macrophages enhances pathogenesis during severe acute respiratory syndrome coronavirus infection. J Virol 2012; 86: 13334-13349.

132 Walter J, Ware LB, Matthay MA. Mesenchymal stem cells: mechanisms of potential therapeutic benefit in ARDS and sepsis. Lancet Respir Med 2014; 2: 1016-1026.

133 Lee J-W, Rocco PRM, Pelosi P. Mesenchymal stem cell therapy for acute respiratory distress syndrome: a light at the end of the tunnel? Anesthesiology 2015; 122: 238-240.

134 Matthay MA, Calfee CS, Zhuo H, et al. Treatment with allogeneic mesenchymal stromal cells for moderate to severe acute respiratory distress syndrome (START study): a randomised phase 2a safety trial. Lancet Respir Med 2019; 7: 154-162.

135 Sánchez-Guijo F, García-Arranz M, López-Parra M, et al. Adipose-derived mesenchymal stromal cells for the treatment of patients with severe SARS-CoV-2 pneumonia requiring mechanical ventilation. A proof of concept study. EClinicalMedicine 2020; 25: 100454

136 Leng Z, Zhu R, Hou W, et al. Transplantation of ACE2- mesenchymal stem cells improves the outcome of patients with COVID-19 pneumonia. Aging Dis 2020; 11: 216-228.

137 Rouse BT, Sehrawat S. Immunity and immunopathology to viruses: what decides the outcome? Nat Rev Immunol 2010; 10: 514-526.

138 Li D, Chen Y, Liu H, et al. Immune dysfunction leads to mortality and organ injury in patients with COVID-19 in China: insights from ERS-COVID-19 study. Signal Transduct Target Ther 2020; 5: 1-3.

139 Channappanavar R, Perlman S. Pathogenic human coronavirus infections: causes and consequences of cytokine storm and immunopathology. Semin Immunopathol 2017; 39: 529-539.

140 Favre D, Lederer S, Kanwar B, et al. Critical loss of the balance between Th17 and T regulatory cell populations in pathogenic SIV infection. PLoS Pathog 2009; 5: e1000295.

141 Rowan AG, Fletcher JM, Ryan EJ, et al. Hepatitis C virus-specific Th17 cells are suppressed by virus-induced TGF-beta. J Immunol 2008; 181: 4485-4494.

142 Bermejo-Martin JF, de Lejarazu R O, Pumarola T, et al. Th1 and Th17 hypercytokinemia as early host response signature in severe pandemic influenza. Crit Care 2009; 13: R201.

143 Wohlleben G, Müller J, Tatsch U, et al. Influenza A Virus infection inhibits the efficient recruitment of Th2 cells into the airways and the development of airway eosinophilia. J Immunol 2003; 170: 4601-4611.

144 Rolot M, Dougall AM, Chetty A, et al. Helminth-induced IL-4 expands bystander memory CD8+T cells for early control of viral infection. Nat Commun 2018; 9: 1-16.

145 Tsitoura DC, Kim S, Dabbagh K, et al. Respiratory infection with influenza A virus interferes with the induction of tolerance to aeroallergens. J Immunol 2000; 165: 3484-3491.

146 Adamko DJ, Yost BL, Gleich GJ, et al. Ovalbumin sensitization changes the inflammatory response to subsequent parainfluenza infection eosinophils mediate airway hyperresponsiveness, M2 muscarinic receptor dysfunction, and antiviral effects. J Exp Med 1999; 190: 1465-1478.

147 Suzuki M, Suzuki S, Yamamoto N, et al. Immune responses against replication-deficient adenovirus inhibit ovalbumin-specific allergic reactions in mice. Hum Gene Ther 2000; 11: 827-838.

148 Yamamoto N, Suzuki S, Suzuki Y, et al. Immune response induced by airway sensitization after influenza A virus infection depends on timing of antigen exposure in mice. J Virol 2001; 75: 499-505.

149 Schwarze J, Hamelmann E, Bradley KL, et al. Respiratory syncytial virus infection results in airway hyperresponsiveness and enhanced airway sensitization to allergen. J Clin Invest 1997; 100: 226-233.

150 Broadhurst R, Peterson R, Wisnivesky JP, et al. Asthma in COVID-19 Hospitalizations: An Overestimated Risk Factor? Ann Am Thorac Soc 2020; in press [https://doi.org/10.1513/AnnalsATS.202006-613RL].

151 Lovinsky-Desir S, Deshpande DR, De A, et al. Asthma among hospitalized patients with COVID-19 and related outcomes. J Allergy Clin Immunol 2020; 146: 1027-1034.

152 Graham BB, Bandeira AP, Morrell NW, et al. Schistosomiasis-associated pulmonary hypertension: pulmonary vascular disease: the global perspective. Chest 2010; 137: 20S-29S.

153 Kumar R, Mickael C, Chabon J, et al. The causal role of IL-4 and IL-13 in Schistosoma mansoni pulmonary hypertension. Am J Respir Crit Care Med 2015; 192: 998-1008.

154 Kimura H, Francisco D, Conway M, et al. Type 2 inflammation modulates ACE2 and TMPRSS2 in airway epithelial cells. J Allergy Clin Immunol 2020; 146: 80-88.

155 Shen Z, Xiao Y, Kang L, et al. Genomic diversity of severe acute respiratory syndrome-coronavirus 2 in patients with coronavirus disease 2019. Clin Infect Dis 2020; 71: 713-720.

156 Kumar R, Nejatizadeh A, Gupta M, et al. The epistasis between vascular homeostasis genes is apparent in essential hypertension. Atherosclerosis 2012; 220: 418-424.

157 Kumar R, Nejatizadeh A, Arif E, et al. Multi-locus interactions of vascular homeostasis genes in essentia hypertension: a gender-based study. Clin Chim Acta 2009; 405: 87-93.

158 Nejatizadeh A, Kumar R, Stobdan T, et al. Significance of angiotensinogen gene haplotypes and genotypes combinations in hypertension. J Hypertens 2008; 26: 1094-1101. 
159 Gupta S, Chattopadhyaya I, Agrawal BK, et al. Correlation of renin angiotensin system (RAS) candidate gene polymorphisms with response to Ramipril in patients with essential hypertension. J Postgrad Med 2015; 61: 21-26.

160 Chen W-J, Yang J-Y, Lin J-H, et al. Nasopharyngeal shedding of severe acute respiratory syndrome-associated coronavirus is associated with genetic polymorphisms. Clin Infect Dis 2006; 42: 1561-1569.

161 Lin M, Tseng H-K, Trejaut JA, et al. Association of HLA class I with severe acute respiratory syndrome coronavirus infection. BMC Med Genet 2003; 4: 9.

$162 \mathrm{Ng} \mathrm{MHL}$, Lau K-M, Li L, et al. Association of human-leukocyte-antigen class I ( $\left.\mathrm{B}^{\star} 0703\right)$ and class II $\left(\mathrm{DRB1}^{\star} 0301\right)$ genotypes with susceptibility and resistance to the development of severe acute respiratory syndrome. J Infect Dis 2004; 190: 515-518.

163 Hsieh Y-H, Chen CWS, Schmitz S-FH, et al. Candidate genes associated with susceptibility for SARS-coronavirus. Bull Math Biol 2010; 72: 122-132.

164 Yuan FF, Velickovic Z, Ashton LJ, et al. Influence of HLA gene polymorphisms on susceptibility and outcome post infection with the SARS-CoV virus. Virol Sin 2014; 29: 128-130. 